\title{
Propionate enhances the expression of key genes involved in the gluconeogenic pathway in bovine intestinal epithelial cells
}

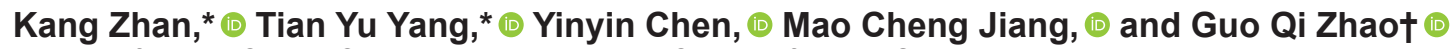 \\ Institute of Animal Culture Collection and Application, College of Animal Science and Technology, Yangzhou University, Yangzhou 225009, China
}

\section{ABSTRACT}

Approximately 15 to $50 \%$ of short-chain fatty acids (SCFA) reach the ruminant small intestine. Previous research suggests that activation of small intestinal gluconeogenesis induced by propionate has beneficial effects on energy homeostasis. However, the regulatory effect of propionate on key gluconeogenic genes in enterocytes of the bovine small intestine remains less known. Therefore, the purpose of this study was to establish the long-term cultures of bovine intestinal epithelial cells (BIEC) from bovine jejunum tissue using SV40T (1:200; Santa Cruz, Shanghai, China) and investigate the regulatory effect of propionate on the key gluconeogenic genes in BIEC. Our study showed that long-term BIEC cultures were established by SV40Tinduced immortalization. Immortal BIEC were distinguished by the expression of cytokeratin 18, villin, fatty acid binding protein 2, and small intestine peptidase. The mRNA expression of genes involved in the SCFA transporters, monocarboxylate transporter 4 , and $\mathrm{Na}^{+} /$ $\mathrm{H}^{+}$exchanger isoforms 1 were significantly elevated with 20 mM SCFA compared with untreated controls. In addition, BIEC exhibited significant uptake of propionate and butyrate from the culture medium. Remarkably, 3 $\mathrm{m} M$ propionate induced profound changes in mRNA level of key genes involved in gluconeogenesis, including phosphoenolpyruvate carboxykinase 2, pyruvate carboxylase, fructose-1,6-bisphosphatase 1, and peroxisome proliferator-activated receptor- $\gamma$ coactivator $1 \alpha$. Additionally, $3 \mathrm{~m} M$ propionate enhanced the expression of PGC1A mRNA at 3,6,12, and $24 \mathrm{~h}$ of incubation. These findings suggest that propionate controls the mRNA expression of genes involved in key enzymes for gluconeogenesis in the enterocytes of bovines.

Key words: bovine intestinal epithelial cell, immortal, gluconeogenesis, propionate

Received July 22, 2019.

Accepted February 8, 2020.

*These authors contributed equally to this work.

†Corresponding author: gqzhao@yzu.edu.cn

\section{INTRODUCTION}

Liver gluconeogenesis plays a vital role in ruminants, and it can produce more than $80 \%$ of glucose in blood (Aschenbach et al., 2010). The ruminant liver mainly uses AA, lactate, pyruvate, and propionate as gluconeogenic substrate to synthesize glucose. Propionate is far more important for ruminants because propionate is typically described as an efficient hepatic gluconeogenic substrate that provides approximately 50 to $60 \%$ of glucose in bovine liver hepatocytes (Huntington, 1990). Propionate is directly absorbed from the rumen epithelium into the hepatic portal venous blood via the rumen epithelial monocarboxylate transporter and solute transporter pathways (Aschenbach et al., 2011). Hypoglycemia and negative energy balance are often observed when liver gluconeogenesis fails to meet increased energy demands in postpartum cattle (Aschenbach et al., 2010). Previous research has found that approximately 15 to $50 \%$ of short-chain fatty acids (SCFA) can pass into the distal parts of the digestive absorption system in ruminants (Aschenbach et al., 2011), indicating that the fractional SCFA can reach the small intestine and that propionate may be absorbed by enterocytes of the small intestine to synthesize glucose for energy requirements. Whether propionate can induce the expression of key genes associated with gluconeogenesis in enterocytes of the bovine small intestine remains unreported.

The propionate-originated gluconeogenic pathway (propionate as a precursor to generate glucose) for the liver of ruminants is stronger than that in monogastric animals (Aschenbach et al., 2010). Propionate can directly enhance the expression of genes involved in the gluconeogenic pathway, including pyruvate carboxylase $(P C)$, cytosolic phosphoenolpyruvate carboxykinase $(P C K 1)$, and mitochondrial phosphoenolpyruvate carboxykinase (PCK2) in bovine calf hepatocytes (Zhang et al., 2016). Pyruvate carboxylase is responsible for converting pyruvate to oxaloacetate in mitochondria, and its promoter is transcriptionally activated by the activation of peroxisome proliferator-activated receptor- $\gamma$ coactivator $1 \alpha$ (PGC-1 $\alpha$; Yoon et al., 2001); PGC-1 $\alpha$ can regulate key mitochondrial genes that contribute 
to the expression of the gluconeogenic pathway (Tiraby and Langin, 2005). Cytosolic phosphoenolpyruvate carboxykinase is responsible for converting oxaloacetate to phosphoenolpyruvate as part of gluconeogenesis in the cytosol, but PCK2 exerts a critical role in converting oxaloacetate to phosphoenolpyruvate in the mitochondria. The oxaloacetate cannot directly cross the mitochondria into the cytosol, and thus PCK2 plays a critical role in converting oxaloacetate to phosphoenolpyruvate in mitochondria. However, the direct effects of propionate on PCK2 mRNA in bovine enterocytes have not been investigated. Propionate induces the expression of key genes involved in gluconeogenesis via a gut-brain axis and positively promotes metabolic benefits in glucose control and energy homeostasis in the small intestine (Delaere et al., 2013; De Vadder et al., 2014). To our knowledge, it is commonly accepted that between 50 and $85 \%$ of SCFA produced by the rumen microbiota are directly absorbed across the reticuloruminal wall, whereas 15 to $50 \%$ of SCFA are not absorbed through the reticulorumen and directly reach the bovine small intestine absorption system (Aschenbach et al., 2011). Although previous studies have focused on the classical gluconeogenic pathway in bovine hepatocytes, we investigated the expression of gluconeogenic genes involved in the propionate-originated pathway (propionate as a precursor to generate glucose) in bovine intestinal epithelial cells (BIEC). We hypothesized that propionate can activate the expression of gluconeogenic genes in enterocytes of the bovine small intestine because propionate promotes the beneficial effects on glucose homeostasis in enterocytes of the small intestine (De Vadder et al., 2014) and reaches the bovine small intestine lumen.

The primary objective of the present study was to establish an immortal BIEC, because primary BIEC culture is often hampered by the level of cell death that occurs when cells are isolated from bovine jejunum epithelium (Zhan et al., 2017), and to determine whether BIEC can transport and take up the propionate. The secondary objective of study was to evaluate the effects of propionate on mRNA expression of key gluconeogenic genes, including mitochondrial $P C K$, $P C$, fructose-1,6-bisphosphatase 1 (FBP1), glucose6-phosphatase $(G 6 P C)$, and $P G C 1 A$ in BIEC.

\section{MATERIALS AND METHODS}

\section{Isolation and Cultivation of Primary Bovine Intestinal Epithelial Cells}

The use of cattle in this study complied with the guidelines of the Institutional Animal Care and Use Committee of Yangzhou University. Bovine jejunum tissues were obtained from 3 newborn Chinese Holstein cows from the experimental farm of Yangzhou University. The jejunum tissue samples were transferred into $30 \mathrm{~mL}$ of Dulbecco's modified Eagle medium (DMEM) supplemented with $10 \%$ fetal bovine serum (Invitrogen, Shanghai, China), $500 \mathrm{U} / \mathrm{mL}$ penicillin, $500 \mu \mathrm{g} / \mathrm{mL}$ streptomycin, and $12.5 \mu \mathrm{g} / \mathrm{mL}$ amphotericin B $(5 \times$ penicillin, streptomycin, and amphotericin; Invitrogen) and immediately transported to the laboratory. The intestinal mesentery was removed from the tissue specimens, which were then repeatedly washed with DMEM (Invitrogen) containing $5 \times$ penicillin, streptomycin, and amphotericin until the supernatant was clear. The intestinal tissue samples were then incubated in PBS digestion solution containing $300 \mathrm{U} /$ $\mathrm{mL}$ collagenase I (Invitrogen) and $0.1 \mathrm{mg} / \mathrm{mL}$ dispase II (Sigma-Aldrich, Shanghai, China) for $30 \mathrm{~min}$ at $37^{\circ} \mathrm{C}$ in a shaking gas bath, and the supernatants were discarded. The remaining intestinal tissues were incubated in the same digestion solution for a further 45 min under the same conditions. The digestion medium was then carefully transferred to a fresh $50-\mathrm{mL}$ tube. The cells were pelleted by centrifugation at $200 \times g$ and $4^{\circ} \mathrm{C}$ for $5 \mathrm{~min}$, and the supernatants were discarded. The cell pellets were resuspended in DMEM containing $10 \%$ fetal bovine serum, $100 \mathrm{U} / \mathrm{mL}$ penicillin, 100 $\mu \mathrm{g} / \mathrm{mL}$ streptomycin, $1 \%$ NEAA, $4 \mathrm{~m} M$ glutamine, 10 $\mu \mathrm{g} / \mathrm{mL}$ insulin, $5.5 \mu \mathrm{g} / \mathrm{mL}$ transferrin, $0.0067 \mu \mathrm{g} / \mathrm{mL}$ sodium selenite (Invitrogen), and $15 \mathrm{ng} / \mathrm{mL}$ epidermal growth factor (Peprotech, Shanghai, China) and seeded in 6 -well plates. Subsequently, the intestinal segments were longitudinally sliced open and the digested mucosa were scraped with a sterile scalpel blade. The scrapings were incubated 3 times in PBS containing $1 \mathrm{mg} / \mathrm{mL}$ dispase II for $10 \mathrm{~min}$ at $37^{\circ} \mathrm{C}$ in a shaking gas bath. Next, the digestion medium was filtered through $74-\mu \mathrm{m}$ nylon mesh to remove the intestinal tissues. The cells were pelleted by centrifugation at $200 \times g$ at $4^{\circ} \mathrm{C}$ for 3 min, and the cell pellets were resuspended in DMEM containing $2 \%$ sorbitol (Sigma-Aldrich) and centrifuged at $50 \times g$ at $4^{\circ} \mathrm{C}$ for $5 \mathrm{~min}$. The supernatants were carefully discarded and the pellets were washed 5 times to remove isolated lymphocytes. Finally, the pellets were resuspended in the same complete medium, and the cells were seeded in 6-well plates and incubated at $37^{\circ} \mathrm{C}$ in $5 \% \mathrm{CO}_{2}$. Complete attachment required up to $48 \mathrm{~h}$, and it was important to not shake the plate during that period.

\section{BIEC Immortalization and Cloning}

Primary BIEC were transduced with lentiviruses expressing SV40 large T antigen using $6 \mu \mathrm{g} / \mathrm{mL}$ polybrene (Sigma-Aldrich) overnight. Next, the viral supernatants 
were carefully removed and the cells were further cultured in medium. After $8 \mathrm{~d}$ of culture, the cells were detached using $0.05 \%$ trypsin and $0.02 \%$ EDTA and then diluted to 5 cells $/ \mathrm{mL}$ in medium. Subsequently, 200- $\mu \mathrm{L}$ aliquots of the cell suspensions were transferred into each well of 96-well plates, and the seeded cells were observed every $5 \mathrm{~d}$. If clusters of cells with epithelial-like and cobblestone morphology reached 50\% confluence, they were expanded. In this way, 3 immortalized BIEC clones were successfully established. The immortalized BIEC were deposited at the Institute of Animal Culture Collection and Application, Yangzhou University.

\section{Identification of Immortalized BIEC}

The success of SV40T transduction was evaluated using Western blotting. To validate the origin of the immortalized BIEC, reverse-transcription PCR (RTPCR) was performed to assess the expression of BIEC markers - namely, villin (VIL1), fatty acid binding protein 2 (FABP2), and small intestine peptidase $(I P)$. Total RNA was extracted using TRIzol (Invitrogen), and RT-PCR was performed using an RT Kit (Roche, Shanghai, China) according to the manufacturer's protocol. The PCR was performed with an initial denaturation at $95^{\circ} \mathrm{C}$ for $600 \mathrm{~s}$, followed by 45 cycles of $95^{\circ} \mathrm{C}$ for $10 \mathrm{~s}, 60^{\circ} \mathrm{C}$ for $10 \mathrm{~s}$, and $72^{\circ} \mathrm{C}$ for $10 \mathrm{~s}$. Each reaction was performed in triplicate. The primers used are listed in Table 1. The PCR products were separated using $1 \%$ agarose gel electrophoresis and visualized using GoldView (Solarbio, Beijing, China) staining.

\section{Immunofluorescence Analysis}

Cells grown on chamber slides were fixed with methanol and acetone for $20 \mathrm{~min}$ at $-20^{\circ} \mathrm{C}$, blocked with PBS containing $3 \%$ horse serum for $1 \mathrm{~h}$ at room temperature, and then incubated with anti-cytokeratin 18 primary antibody (1:1,000; Abcam, Shanghai, China) overnight at $4^{\circ} \mathrm{C}$. Next, cells were incubated with fluorescein isothiocyanate-conjugated anti-mouse IgG (1:400; Santa Cruz, Shanghai, China) for $45 \mathrm{~min}$ and washed gently in PBS. Cell nuclei were stained with 4',6-diamidino-2-phenylindole for $5 \mathrm{~min}$, and the slides were washed in PBS. Finally, coverslips were mounted on chamber slides using PermaFluor mounting medium (Thermo Scientific, Shanghai, China), and the cells were observed using a confocal laser scanning microscope (Olympus, Tokyo, Japan).

\section{Proliferative Activity Analysis}

Cells were seeded in 24 -well plates at $5 \times 10^{3}$ cells/ well to obtain growth curves. Cells were counted in triplicate wells from d 2 to 7 , and the growth curves of mean cell numbers were plotted.

Table 1. Primers for real-time PCR analyses

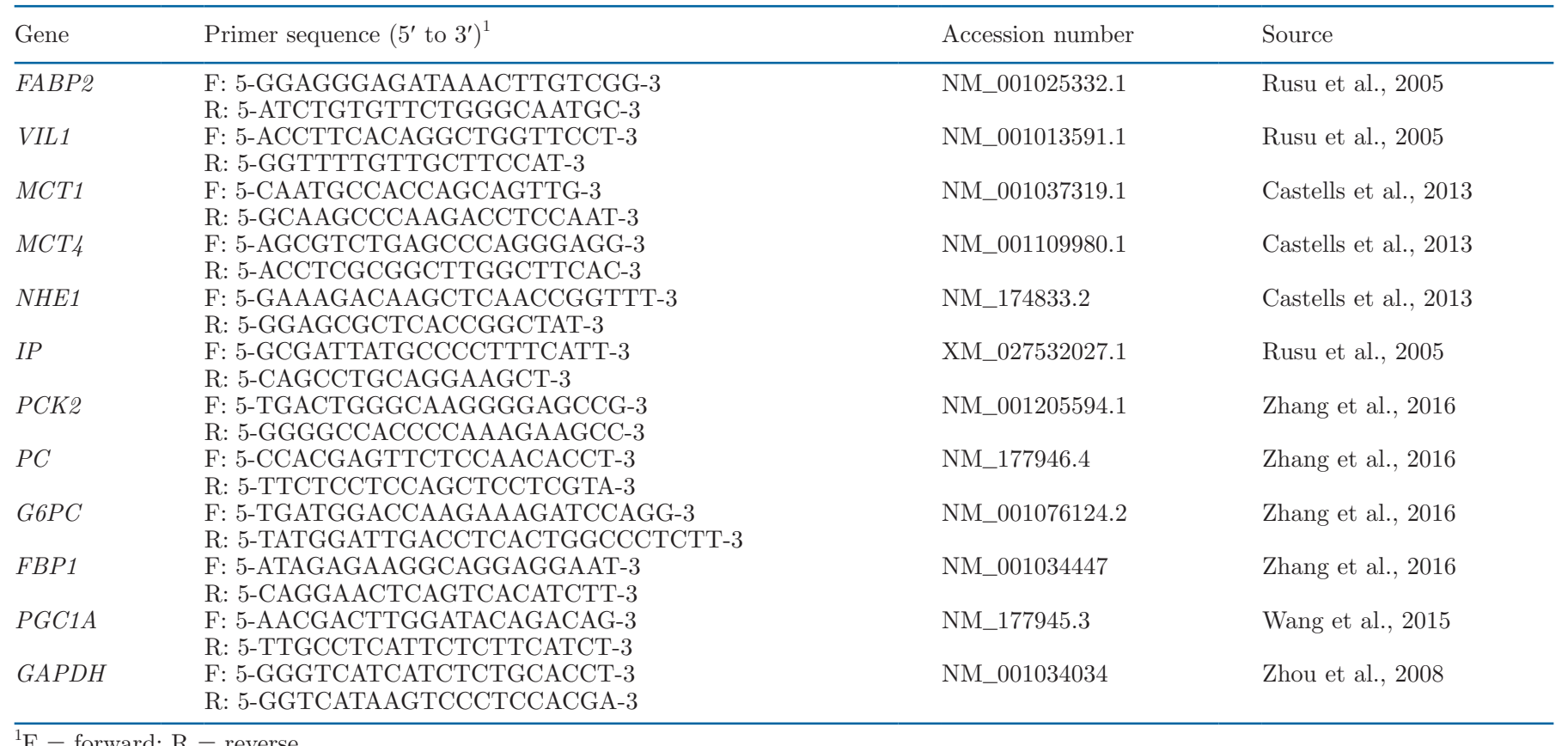

${ }^{1} \mathrm{~F}=$ forward; $\mathrm{R}=$ reverse. 


\section{Analysis of SCFA Uptake}

The BIEC were seeded in 24 -well plates $\left(4.5 \times 10^{4}\right.$ cells/well) for SCFA uptake analysis. The experiment included 2 experimental groups as follows: cell medium containing $20 \mathrm{~m} M$ SCFA only (control group), and BIEC cultured with $20 \mathrm{~m} M$ SCFA (treatment group). After $24 \mathrm{~h}$ of incubation, supernatant medium was collected and transferred to $-80^{\circ} \mathrm{C}$ before analysis of the acetate, propionate, and butyrate concentrations, which were measured using an Agilent $6890 \mathrm{~N}$ gas chromatograph fitted with a TDX-01 packed column (1 m $\times 3 \mathrm{~mm} \times 2 \mathrm{~mm}$; Benfen Ruili Instrument Co., Beijing, China) as previously described (Kles and Chang, 2006). The mixture of $20 \mathrm{~m} M$ SCFA contained $12 \mathrm{~m} M$ sodium acetate, $5 \mathrm{~m} M$ sodium propionate, and $3 \mathrm{~m} M$ sodium butyrate (Sigma).

\section{Cell Culture}

The BIEC were seeded in 6 -well plates $\left(2 \times 10^{5}\right.$ cells $/$ well) for mRNA expression analysis. For the evaluation of the mRNA levels of genes involved in SCFA transporters, cells were divided into 6 experimental groups in the following manner: cells were cultured in $\mathrm{pH} 6.2, \mathrm{pH}$ 6.8 , and $\mathrm{pH} 7.4$ medium in the absence (control groups) or presence (treatment groups) of $20 \mathrm{mM}$ SCFA. The SCFA mixtures contained $12 \mathrm{~m} M$ sodium acetate, 5 $\mathrm{m} M$ sodium propionate, and $3 \mathrm{~m} M$ sodium butyrate (Sigma-Aldrich). For $\mathrm{pH}$ adjustment, the medium was acidified using $1 \mathrm{M} \mathrm{HCl}$.

The expression of these genes was investigated in the presence of $0,0.75,1.5$, and $3 \mathrm{mM}$ propionate for $24 \mathrm{~h}$. The expression of these genes in BIEC was determined in the presence of either 0 or $3 \mathrm{~m} M$ propionate for 1,3 , 6,12 , and $24 \mathrm{~h}$. After incubation, these cells were collected for RNA extraction, and the RNA samples were transferred to $-80^{\circ} \mathrm{C}$ until analysis by quantitative (q) RT-PCR.

\section{qRT-PCR}

Measurement of qRT-PCR was performed as described previously (Gong et al., 2018). Total RNA was isolated from cultured cells using TRIzol reagent (Tiangen, Beijing, China). Reverse transcription was performed using an RT Kit (code no. RR036A; Takara, Kyoto, Japan). The reverse transcription reaction mixtures contained $1 \mu \mathrm{g}$ of total RNA and $5 \times$ PrimeScript RT Master Mix (Takara) in a final volume of $20 \mu \mathrm{L}$. The reverse transcription reactions were performed for $15 \mathrm{~min}$ at $37^{\circ} \mathrm{C}$. Reverse transcriptase was inactivated by heating to $85^{\circ} \mathrm{C}$ for $5 \mathrm{~s}$. The qRT-PCR was performed with a SYBR Premix Ex TaqII Kit (code no. RR820A and RR420A; Takara). The qRT-PCR included an initial denaturation at $95^{\circ} \mathrm{C}$ for $30 \mathrm{~s}$, followed by 40 cycles at $95^{\circ} \mathrm{C}$ for $5 \mathrm{~s}$ and $60^{\circ} \mathrm{C}$ for $30 \mathrm{~s}$. These primers used are listed in Table 1 . The relative expression of target genes was normalized to that of GAPDH and calculated using the $2^{-\Delta \Delta \mathrm{CT}}$ method.

\section{Western Blotting Analysis}

Cells were lysed to extract total protein in radioimmunoprecipitation assay buffer containing protease inhibitors. The protein concentrations were determined using a BCA kit (Beyotime, Shanghai, China). Equal amounts of protein lysates were fractionated by SDSPAGE and transferred to nitrocellulose membranes (Pall, Shanghai, China). Membranes were blocked with $5 \%$ skim milk and then incubated with gentle shaking overnight at $4{ }^{\circ} \mathrm{C}$ with the primary antibody plus $5 \%$ horse serum in Tris-buffered saline with Tween $(10 \mathrm{mM}$ Tris-HCl, pH 7.5, $150 \mathrm{mM} \mathrm{NaCl}, 0.05 \%$ Tween 20). The following primary antibodies were used: SV40T (1:200; Santa Cruz, Shanghai, China). Horseradish peroxidaseconjugated secondary antibodies were horse anti-mouse IgG (1:5,000; CST, Shanghai, China). Target bands were detected using Pierce ECL Plus Western Blotting Substrate (Thermo Scientific).

\section{Statistical Analysis}

Before data analysis, the distribution of normality and homogeneity of variances was studied with Kolmogorov-Smirnov and Levene's tests, respectively. Data were in accord with the distribution of normality and homogeneity of variance, and statistical analysis was evaluated using 1-way ANOVA, followed by determination of the least significant difference for post hoc multiple comparisons of treatment means using SPSS 19.0 (SPSS Inc., Chicago, IL). A Kruskal-Wallis test was performed using the nonparametric test for statistical analysis. The experiment was divided into 2 groups, and statistical analysis was tested using the independent samples $t$-test. The MCT1, MCT4, and NHE1 gene expressions for the $2^{-\Delta \Delta \mathrm{Ct}}$ assays were $\log _{10}$ transformed for statistical analysis; $P<0.05$ was considered significant, and $P<0.01$ was considered highly significant. Trends toward significance are discussed at $0.05<P<0.10$.

\section{RESULTS}

\section{Characterization of the Morphology of Primary BIEC}

We isolated primary BIEC from bovine jejunum tissue using a combination of collagenase and dispase. 

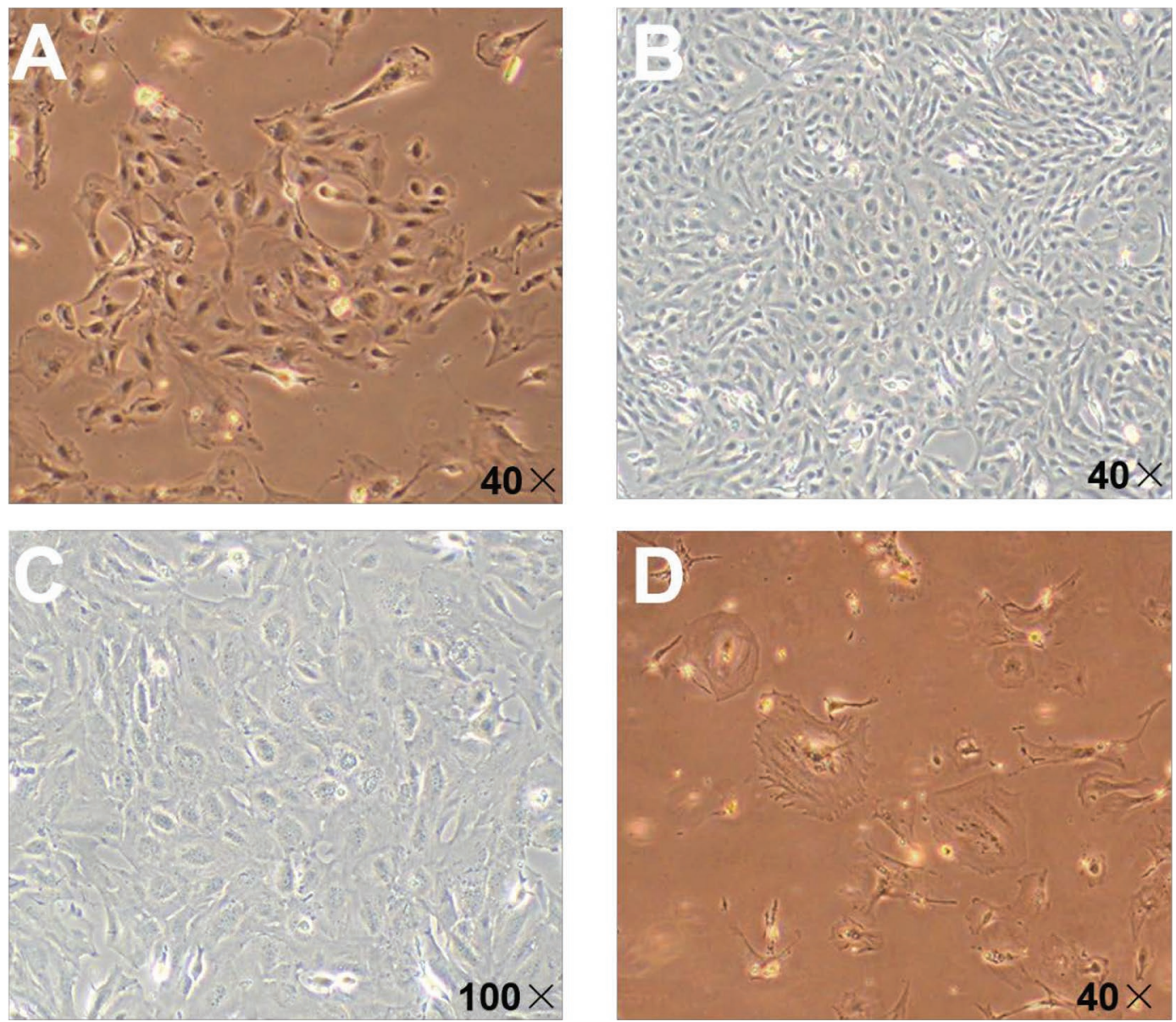

Figure 1. Morphology of primary cell cultures. (A) Adherence and slow proliferation of epithelial-like cells. (B) Confluent monolayer of epithelial-like cells that formed within $5 \mathrm{~d}$ of isolation. (C) Close-up of a dome that formed from the confluent monolayer. (D) Epithelial-like cell senescence. Image magnification: $40 \times$ or $100 \times$.

Some cells adhered and proliferated slowly within 48 h postisolation (Figure 1A). Cells with epithelial-like morphology started to proliferate rapidly and reached monolayer confluence within 5 d of culture postisolation (Figure 1B). Confluent monolayer BIEC produced dome structures (Figure 1C). Subsequently, epitheliallike cells exhibited a state of replicative senescence, which was typically characterized by cytoplasm elongation and development of multiple nuclei within $20 \mathrm{~d}$ of culture postisolation (Figure 1D).

\section{Establishment and Characterization of Immortalized BIEC}

To overcome BIEC senescence, BIEC were immortalized using SV40T. The SV40T band was observed using immunoblotting (Figure 2A). In addition, immortalized BIEC were cultured for at least 50 passages without showing any signs of senescence. The immortalized BIEC were strongly immunopositive for cytokeratin 18
(Figure 2B). These results indicate that the immortalized BIEC originated from epithelial-type cells. To further evaluate the expression of BIEC marker genes, FABP2, VIL1, and IP were analyzed using RT-PCR; FABP2 and IP are believed to be bovine enterocyte markers, whereas villin is an intestine-specific microvillus protein that is found only in gastrointestinal epithelial cells. The RT-PCR analyses confirmed the presence of FABP2, IP, and VIL1 mRNA in immortalized BIEC (Figure 2C). The immortalized BIEC proliferated robustly within $5 \mathrm{~d}$ of culture postseeding. In contrast, primary BIEC exhibited slow proliferation (Figure 2D). These results indicate that the immortalized BIEC originated from intestinal epithelial cells.

\section{Effects of SCFA and pH on the Expression of Genes Involved in SCFA Transporters}

The mRNA levels of MCT1 were enhanced in the combination of $\mathrm{pH} 7.4$ and $20 \mathrm{~m} M$ SCFA compared 

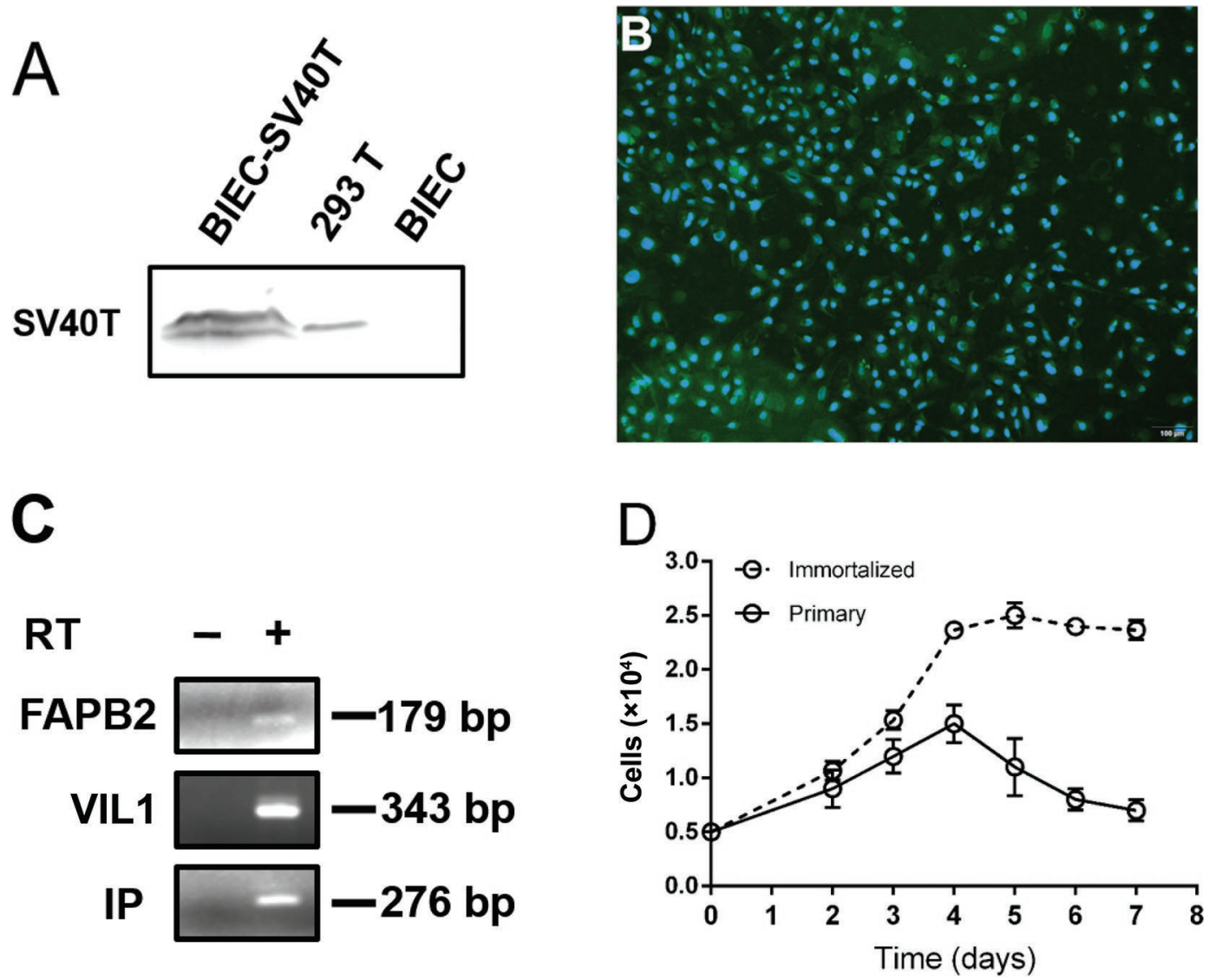

Figure 2. Characteristics of immortalized bovine intestinal epithelial cells. (A) Immunoblotting of SV40T (Santa Cruz, Shanghai, China). BIEC (bovine intestinal epithelial cells) = uninfected, negative control; 293T = positive control; BIEC-SV40T = infected cells used in the present study. (B) Indirect immunofluorescence of cytokeratin 18 (green). Nuclei were stained with 4',6-diamidino-2-phenylindole (blue). (C) Reverse-transcription PCR analyses of fatty acid binding protein 2 (FABP2), villin (VIL1), and small intestine peptidase (IP). To exclude amplification from genomic DNA contamination. RNA was treated with either DNase before reverse transcription or a control without reverse transcriptase ( $\mathrm{RT}-=$ negative control). (D) Growth curves of immortalized and primary BIEC. Data are means \pm SEM $(\mathrm{n}=3$ ).

with the untreated groups at $\mathrm{pH} 6.8(P=0.007)$ and $\mathrm{pH} 7.4(P=0.003)$ or the combination of $20 \mathrm{~m} M \mathrm{SCFA}$ at $\mathrm{pH} 6.2(P=0.017)$ and $\mathrm{pH} 6.8(P=0.03)$. In ad- dition, the combination of $20 \mathrm{~m} M$ SCFA and $\mathrm{pH} 7.4$ enhanced $(P<0.01)$ the expression of $M C T 4$ relative to others groups (Figure 3B). The mRNA levels of
A

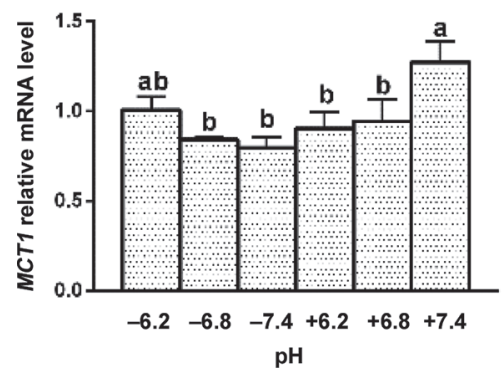

B

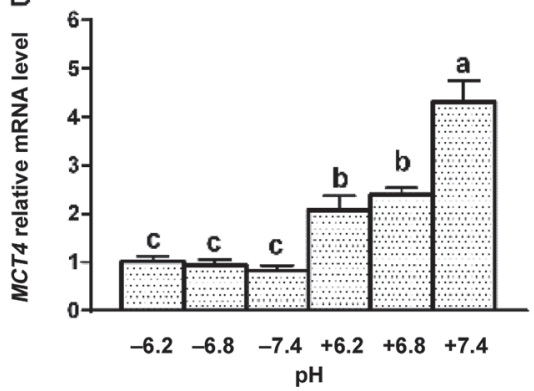

C

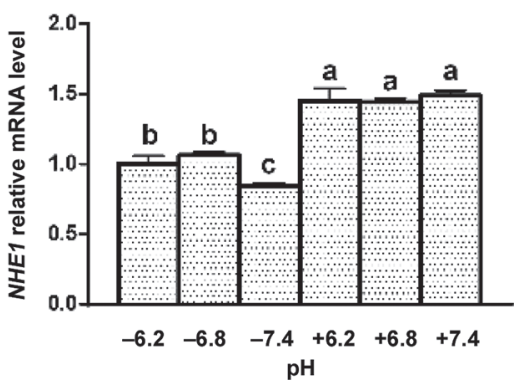

Figure 3. Effects of short-chain fatty acids (SCFA) and pH on the mRNA levels of genes encoding SCFA transporters. Bovine intestinal epithelial cells were cultured at $\mathrm{pH} 6.2,6.8$, and 7.4 in the absence (controls) or presence (treatment groups) of $20 \mathrm{~m} M$ SCFA for 24 h. The 20 $\mathrm{m} M$ SCFA mixture consisted of $12 \mathrm{~m} M$ sodium acetate, $5 \mathrm{~m} M$ sodium propionate, and $3 \mathrm{~m} M$ sodium butyrate. Levels of (A) $M C T 1$, (B) $M C T 4$, and (C) NHE1 are shown. GAPDH was used as an internal reference gene. Data are means $\pm \mathrm{SEM}(\mathrm{n}=3$ ). Different letters (a-c) indicate significant differences. 
MCT4 were enhanced in the combinations of $20 \mathrm{mM}$ SCFA at $\mathrm{pH} 6.2(P<0.01)$ and $\mathrm{pH} 6.8(P<0.01)$ compared with the $\mathrm{pH} 6.2$ and $\mathrm{pH} 6.8$ treatments without $20 \mathrm{~m} M$ SCFA (Figure 3B). The expression of NHE1 was increased $(P<0.001)$ by addition of $20 \mathrm{~m} M$ SCFA compared with the absence of $20 \mathrm{~m} M$ SCFA (Figure $3 \mathrm{C})$. These results indicate that high $\mathrm{pH}$ and addition of SCFA can enhance the expression of genes involved in SCFA transporters in BIEC.

\section{Uptake of SCFA}

To investigate whether BIEC can absorb acetate, propionate, and butyrate, their concentrations were measured in medium supernatant. The concentrations of acetate $(P=0.081)$ and total SCFA $(P=0.063)$ tended to be decreased in BIEC culture medium (Figure $4 \mathrm{~A}$ and $\mathrm{D})$. Notably, propionate $(P=0.042)$ and butyrate $(P=0.049)$ concentrations were markedly reduced in medium after culture of BIEC (Figure 4B and $\mathrm{C}$ ). These results suggest that BIEC can transport and absorb propionate and butyrate.

\section{Effects of Increasing Propionate Concentration and Time Point on the Expression of Key Genes Encoding the Gluconeogenic Pathway}

The mRNA expression of genes related to gluconeogenesis, including $P C K 2, P C, F B P 1, G 6 P C$, and $P G$ $C 1 A$, was investigated using qRT-PCR. Compared with the absence of propionate, addition of $3 \mathrm{~m} M$ propionate enhanced the mRNA levels of $P C K 2(P=0.001), P C(P$ $=0.007), F B P 1(P<0.001)$, and $P G C 1 A(P=0.001)$, but the expression of $G 6 P C$ mRNA was not profoundly altered $(P>0.10)$ by any of the concentrations tested (Table 2). At 1, 3, 6, and $12 \mathrm{~h}$ of incubation, no effect of propionate on the mRNA expression of $P C K 2$ and $P C$ was observed (Figure 5A and D; $P>0.05$ ). In contrast, a treatment by $24 \mathrm{~h}$ of incubation was observed $(P<$ 0.05 ) for an evaluation in the expression $P C K 2$ and $P C$ in response to $3 \mathrm{mM}$ propionate treatment (Figure 5A and $\mathrm{D})$. At $3 \mathrm{~h}$ of incubation, propionate significantly enhanced $(P=0.006)$ the expression of FBP1 mRNA relative to the untreated group (Figure 5C), whereas the response to propionate dissipated at 6 and $12 \mathrm{~h}$ of incubation. Interestingly, the response to propionate was found in the expression of FBP1 at $24 \mathrm{~h}$ of incubation. An increase in time from 3 to $24 \mathrm{~h}$ enhanced $(P<0.05)$ the expression of $P G C 1 A$ by propionate treatment (Figure $5 \mathrm{E}$ ). However, mRNA expression of $G 6 P C$ was not changed $(P>0.05)$ by propionate at any time point detected (Figure $5 \mathrm{~B}$ ).

\section{DISCUSSION}

In the present study, immortalized BIEC were established and validated for application in the investigation of the effects of propionate on the expression of key genes encoding the gluconeogenic pathway. Bovine intestinal epithelial cells are key target cells for SCFA uptake; however, primary BIEC culture is difficult because of the amount of programmed cell death that occurs after cells are isolated from the bovine intestinal epithelium (Zhan et al., 2017). To avoid induction of programmed cell death in vitro, we therefore established immortalized BIEC lines by transformation using SV40T antigen. The immortal BIEC line has undergone at least 50 passages without showing any signs of senescence. To validate the origin of the immortal BIEC line, we first conducted immunocytochemical analysis of cytokeratin 18. The BIEC were strongly immunopositive for cytokeratin 18, which is used to distinguish cells of epithelial origin from stellate cells (Miyazawa et al., 2010; Zhan et al., 2018). This result indicates that the immortalized BIEC originated from epithelial-type cells. Moreover, we demonstrated that the BIEC line expressed FABP2, VIL1, and IP. The fatty acid binding protein family consists of FABP1, FABP2, FABP3, FABP4, and FABP5, which are expressed in different tissues; $F A B P 2$ is an intestinal-specific marker, which exhibits constant expression in both jejunocytes and colonocytes (Rusu et al., 2005). Our results confirmed that the BIEC line expressed the mRNA of FABP2. Villin is a protein specific to the intestinal microvilli and is detected only in gastrointestinal epithelial cells (George et al., 2007). The VIL1 mRNA was highly expressed in the BIEC line. These data suggest that the BIEC line originates from enterocytes. The $I P$ is an important tissue-specific marker detected only in jejunocytes, and it is responsible for processing and absorption of dietary peptides (Lyons and Fricker, 2011). Small intestine peptidase can be expressed in the BIEC line, indicating that BIEC may be able to produce peptides using intestinal peptidase to hydrolyze proteins. These results demonstrated that the immortal BIEC line originates from bovine enterocyte cells.

Although previous studies have focused on the classical gluconeogenic pathway in bovine hepatocytes, the effect of propionate on expression of gluconeogenic genes in enterocytes of the bovine small intestine is less known. Previous studies demonstrated that SCFA are absorbed by the human ileum (Schmitt et al., 1977). The SCFA are the major anions in the intestinal lumen and a gastrointestinal-specific energy source that is easily absorbed and metabolized (Schmitt et al., 1977). In addition, approximately 15 to $50 \%$ of SCFA can pass 
Table 2. Expression of genes involved in the gluconeogenesis pathway in bovine intestinal epithelial cells incubated with propionate

\begin{tabular}{lcccccc}
\hline & \multicolumn{5}{c}{ Treatment $^{1}$} \\
Gene & $0 \mathrm{~m} M$ & $0.75 \mathrm{~m} M$ & $1.5 \mathrm{mM}$ & $3 \mathrm{~m} M$ & SEM & $P$-value \\
\cline { 2 - 5 } PCK2 & $1.00^{\mathrm{c}}$ & $1.33^{\mathrm{ab}}$ & $1.22^{\mathrm{b}}$ & $1.48^{\mathrm{a}}$ & 0.06 & 0.003 \\
PC & $1.01^{\mathrm{b}}$ & $0.98^{\mathrm{b}}$ & $0.90^{\mathrm{b}}$ & $1.34^{\mathrm{a}}$ & 0.57 & 0.007 \\
$F B P 1$ & $1.13^{\mathrm{c}}$ & $3.71^{\mathrm{b}}$ & $2.46^{\mathrm{bc}}$ & $9.13^{\mathrm{a}}$ & 0.97 & $<0.001$ \\
G6PC & 1.00 & 0.97 & 1.00 & 1.02 & 0.03 & 0.95 \\
PGC1A & $1.14^{\mathrm{b}}$ & $2.40^{\mathrm{b}}$ & $2.61^{\mathrm{b}}$ & $4.30^{\mathrm{a}}$ & 0.38 & 0.006 \\
\hline
\end{tabular}

${ }^{\mathrm{a}-\mathrm{c}}$ Means within a row with different superscripts differ significantly for treatment effect $(P<0.05)$.

${ }^{1}$ Bovine intestinal epithelial cells were cultured in Dulbecco's modified Eagle medium/F12 medium with 0 (control), 0.75, 1.5, or $3 \mathrm{mM}$ propionate for $24 \mathrm{~h}$ in vitro.

into the distal parts of the digestive absorption system in ruminants (Aschenbach et al., 2011). Our present results demonstrate that BIEC exhibited significant propionate and butyrate uptake, indicating that propionate may induce the expression of key gluconeogenic genes in enterocytes of the bovine small intestine. The gluconeogenic pathway contains 4 key rate-limiting enzymes, including PC, PCK, FBP1, and G6PC. The PC enzyme requires ATP to catalyze the carboxylation of pyruvate to oxaloacetate in mitochondria. The lack of oxaloacetate inhibits the tricarboxylic acid cycle and is often associated with negative energy balance and ketosis in dairy cows (Herdt, 2000). The mRNA expression of $P C$ is enhanced at postpartum dairy cow response to more oxaloacetates to increase gluconeogenesis from lactate and glycogenic AA (Greenfield et al., 2000). Our results show that addition of $3 \mathrm{~m} M$ propionate induces the expression of $P C$ relative to the control group. The formation of oxaloacetate in mitochondria cannot directly cross the mitochondrial membrane, and oxaloacetate is converted into malic acid by malic dehydrogenase. Malic acid can directly cross the mitochondrial membrane and is converted into oxaloacetate by malic dehydrogenase in the cytosol. Cytosolic PCK1 catalyzes formation of phosphoenolpyruvate from oxaloacetate, a critical reaction for gluconeogenesis. However, our present study shows that the expression of PCK1 was not observed by addition of propionate in BIEC. Cytosolic PCK1 expression was elevated by addition of propionate and cyclic adenosine monophosphate (cAMP) in bovine hepatocytes, but addition of insulin
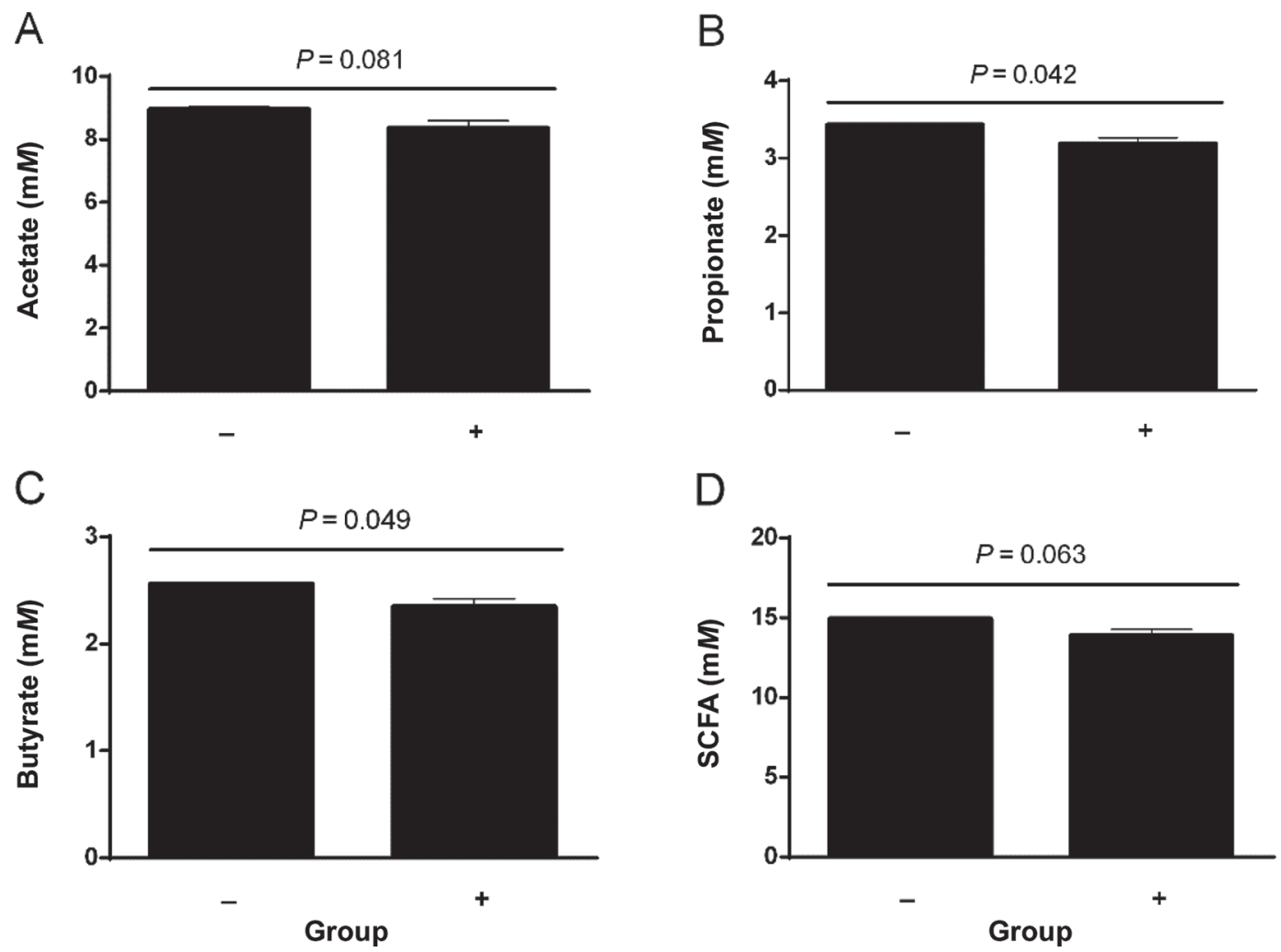

Figure 4. Analysis of short-chain fatty acid (SCFA) uptake. Cells were divided into 2 experimental groups: medium containing $20 \mathrm{~m} M$ SCFA alone (control group; -) and bovine intestinal epithelial cells incubated with $20 \mathrm{~m} M$ SCFA (treatment group; +) for $24 \mathrm{~h}$. The $20 \mathrm{~m} M$ SCFA mixture consisted of $12 \mathrm{~m} M$ sodium acetate, $5 \mathrm{~m} M$ sodium propionate, and $3 \mathrm{~m} M$ sodium butyrate. The levels of (A) acetate, (B) propionate, (C) butyrate, and (D) total SCFA were determined using gas chromatography. Data are means \pm SEM $(\mathrm{n}=3)$. 
shows a decrease in the expression of PCK1 (Zhang et al., 2016). Interestingly, addition of propionate significantly enhanced the expression of PCK2 compared with the control group. Previous research reported that expression of PCK2 is not regulated by physiologically relevant concentration, cAMP, or insulin (White et al., 2012; Zhang et al., 2016). However, propionate activates the mRNA expression of $P C K 2$ in a concentrationdependent manner in bovine hepatocytes (Zhang et al., 2016). The overexpression of PCK2 plays a critical role in gluconeogenesis and lipid metabolism in human liver (Méndez-Lucas et al., 2013). In the liver of monogastric animals, PCK2 accounts for only approximately 1 to $5 \%$ of total phosphoenolpyruvate carboxykinase activity (Wiese et al., 1991), but ruminants show approximately equal activities of PCK1 and PCK2 (Agca et al., 2002). PCK2 catalyzes the conversion of oxaloacetate to phosphoenolpyruvate in mitochondria, acting as a critical rate-limiting enzyme in gluconeogenesis. The phosphoenolpyruvate, as a gluconeogenic precursor substance, produced by PCK2 can directly cross the mitochondrial membrane into cytosol to perform gluconeogenesis, suggesting that PCK2 exerts a critical role and higher efficiency than PCK1 for the gluconeogenic pathway in ruminants. In the present study, our results demonstrate that $P C K 2$ plays a critical role for converting oxaloacetate to phosphoenolpyruvate and gluconeogenic pathway in enterocytes of the bovine small intestine.

The function of FBP1 catalyzes the hydrolysis of fructose 1,6-bisphosphate to fructose 6-phosphate. A lack of ATP can decrease the activity of FBP1 and fructose 6 -phosphate production and ultimately reduce glucose production (Wang et al., 2015). Our result shows that 3 $\mathrm{m} M$ propionate exhibits 8-fold change in the expression of FBP1 mRNA compared with the absence of propionate, suggesting that propionate can induce more fructose 6-phosphate production for glucose synthesis in enterocytes of the bovine small intestine. However, propionate did not promote the expression of G6PC mRNA in BIEC, although it induces the key genes involved in other gluconeogenesis, which is consistent with the previous finding that mRNA expression of $G 6 P C$ is not altered by addition of propionate, cAMP, or insulin in bovine hepatocytes (Zhang et al., 2016). However, expression of $G 6 P C$ is transcriptionally regulated by glucocorticoids, cAMP, and insulin in monogastric animals (van Schaftingen and Gerin, 2002). In addition, G6PC activity tended to be decreased in prepartum cows (Murondoti et al., 2004). Dairy cows infused with
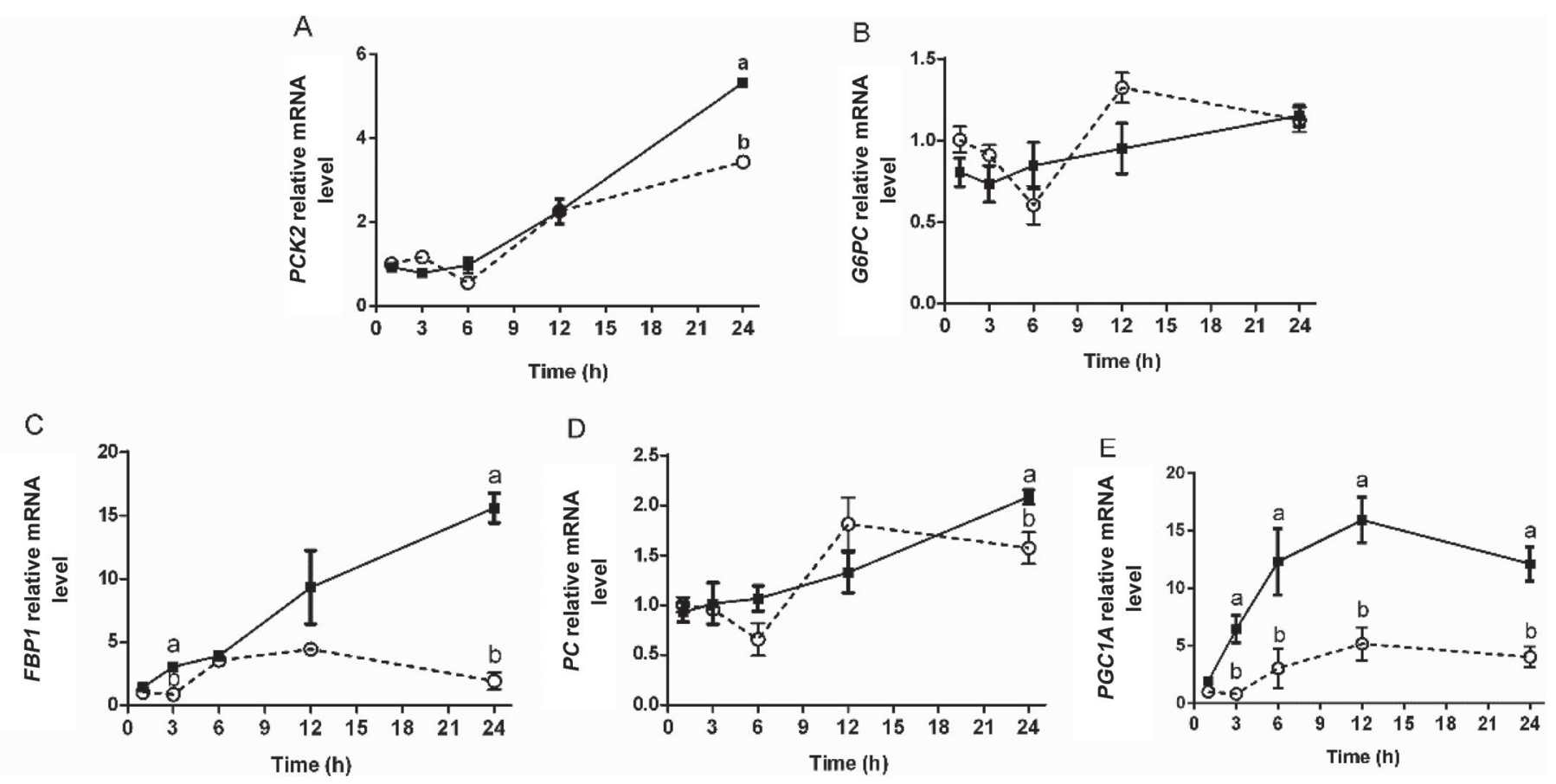

Figure 5. Effects of propionate on the mRNA levels of key genes involved in the gluconeogenesis pathway. Bovine intestinal epithelial cells were exposed to either 0 (dotted line, open circle) or $3 \mathrm{mM}$ (solid line, solid square) propionate for the interval of time indicated and harvested for mRNA level analysis. Quantitative reverse-transcription PCR analysis of (A) mitochondrial phosphoenolpyruvate carboxykinase 2 ( $P C K 2)$, (B) glucose-6-phosphatase $(G 6 P C)$, (C) fructose-1,6-bisphosphatase 1 (FBP1), (D) pyruvate carboxylase $(P C)$, and (E) peroxisome proliferatoractivated receptor- $\gamma$ coactivator $1 \alpha(P G C 1 A)$ in bovine intestinal epithelial cells. GAPDH was used as an internal reference gene. Data are means $\pm \operatorname{SEM}(\mathrm{n}=3)$. Different letters $(\mathrm{a}, \mathrm{b})$ indicate significant differences. 
glucose did not experience a profound change in G6PC protein abundance (Al-Trad et al., 2010). PGC1A is a transcriptional coactivator that regulates the genes associated with energy metabolism (Yoon et al., 2001; Miller and Birnbaum, 2010). In addition, PGC1A is a critical protein in upregulating the expression of gluconeogenic genes and alters the transcriptional activity of the PCK promoter to regulate the level of PCK in liver (Yoon et al., 2001). Our present data show that an increase in time from 3 to $24 \mathrm{~h}$ significantly increased the expression of $P G C 1 A$ with propionate treatment relative to the absence of propionate. Furthermore, $P G C 1 A$ was markedly enhanced by treatment with 3 $\mathrm{m} M$ propionate compared with other any groups. In the present study, the increased expression of $P G C 1 A$ indicated that elevated $P C K 2, P C$, and FBP1 mRNA levels have occurred in BIEC. Our data demonstrate that propionate can enhance the mRNA expression of PCK2, PC, FBP1, and PGC1A in BIEC and that $P C K 2$ plays a critical role for gluconeogenic pathway in enterocytes of the bovine small intestine.

\section{CONCLUSIONS}

In this study, we established the immortal BIEC lines that maintain typical epithelial-like morphology. Immortal BIEC express the enterocyte markers FABP2, VIL1, and IP and can absorb propionate. Our investigation also reveals a novel role of propionate to induce the mRNA expression of genes involved in key enzymes for gluconeogenesis and PCK2 exerts a key role in the gluconeogenic pathway in enterocytes of the bovine small intestine.

\section{ACKNOWLEDGMENTS}

This study was supported by the National Natural Science Foundation of China (no. 31972589), the Research Project of Natural Science Foundation of Jiangsu Province (SBK2019043455), China Agriculture Research System (CARS-36), and Development Project of China (2017YFD0502104-3). The authors have not stated any conflicts of interest.

\section{REFERENCES}

Agca, C., R. B. Greenfield, J. R. Hartwell, and S. S. Donkin. 2002. Cloning and characterization of bovine cytosolic and mitochondrial PEPCK during transition to lactation. Physiol. Genomics 11:53-63. https://doi.org/10.1152/physiolgenomics.00108.2001.

Al-Trad, B., T. Wittek, G. B. Penner, K. Reisberg, G. Gabel, M. Furll, and J. R. Aschenbach. 2010. Expression and activity of key hepatic gluconeogenesis enzymes in response to increasing intravenous infusions of glucose in dairy cows. J. Anim. Sci. 88:2998-3008. https: //doi.org/10.2527/jas.2009-2463.
Aschenbach, J. R., N. B. Kristensen, S. S. Donkin, H. M. Hammon, and G. B. Penner. 2010. Gluconeogenesis in dairy cows: The secret of making sweet milk from sour dough. IUBMB Life 62:869-877. https://doi.org/10.1002/iub.400.

Aschenbach, J. R., G. B. Penner, F. Stumpff, and G. Gabel. 2011. Ruminant Nutrition Symposium: Role of fermentation acid absorption in the regulation of ruminal pH. J. Anim. Sci. 89:1092-1107. https://doi.org/10.2527/jas.2010-3301.

Castells, L., A. Bach, A. Aris, and M. Terre. 2013. Effects of forage provision to young calves on rumen fermentation and development of the gastrointestinal tract. J. Dairy Sci. 96:5226-5236. https:// doi.org/10.3168/jds.2012-6419.

De Vadder, F., P. Kovatcheva-Datchary, D. Goncalves, J. Vinera, C. Zitoun, A. Duchampt, F. Backhed, and G. Mithieux. 2014 Microbiota-generated metabolites promote metabolic benefits via gut-brain neural circuits. Cell 156:84-96. https://doi.org/10.1016/ j.cell.2013.12.016.

Delaere, F., A. Duchampt, L. Mounien, P. Seyer, C. Duraffourd, C. Zitoun, B. Thorens, and G. Mithieux. 2013. The role of sodiumcoupled glucose co-transporter 3 in the satiety effect of portal glucose sensing. Mol. Metab. 2:47-53. https://doi.org/10.1016/j .molmet.2012.11.003.

George, S. P., Y. Wang, S. Mathew, K. Srinivasan, and S. Khurana. 2007. Dimerization and actin-bundling properties of villin and its role in the assembly of epithelial cell brush borders. J. Biol. Chem. 282:26528-26541. https://doi.org/10.1074/jbc.M703617200.

Gong, X. X., X. S. Su, K. Zhan, and G. Q. Zhao. 2018. The protective effect of chlorogenic acid on bovine mammary epithelial cells and neutrophil function. J. Dairy Sci. 101:10089-10097. https:// doi.org/10.3168/jds.2017-14328.

Greenfield, R. B., M. J. Cecava, and S. S. Donkin. 2000. Changes in mRNA expression for gluconeogenic enzymes in liver of dairy cattle during the transition to lactation. J. Dairy Sci. 83:1228-1236. https://doi.org/10.3168/jds.S0022-0302(00)74989-7.

Herdt, T. H. 2000. Ruminant adaptation to negative energy balance. Influences on the etiology of ketosis and fatty liver. Vet. Clin. North Am. Food Anim. Pract. 16:215-230. https://doi.org/10 .1016/S0749-0720(15)30102-X.

Huntington, G. B. 1990. Energy metabolism in the digestive tract and liver of cattle: Influence of physiological state and nutrition. Reprod. Nutr. Dev. 30:35-47. https://doi.org/10.1051/rnd:19900103.

Kles, K. A., and E. B. Chang. 2006. Short-chain fatty acids impact on intestinal adaptation, inflammation, carcinoma, and failure. Gastroenterology 130(Suppl. 1):S100-S105. https://doi.org/10.1053/j .gastro.2005.11.048.

Lyons, P. J., and L. D. Fricker. 2011. Carboxypeptidase O is a glycosylphosphatidylinositol-anchored intestinal peptidase with acidic amino acid specificity. J. Biol. Chem. 286:39023-39032. https:// doi.org/10.1074/jbc.M111.265819.

Méndez-Lucas, A., J. A. G. Duarte, N. E. Sunny, S. Satapati, T. T. He, X. Fu, J. Bermúdez, S. C. Burgess, and J. C. Perales. 2013. PEPCK-M expression in mouse liver potentiates, not replaces, PEPCK-C mediated gluconeogenesis. J. Hepatol. 59:105-113. https://doi.org/10.1016/j.jhep.2013.02.020.

Miller, R. A., and M. J. Birnbaum. 2010. An energetic tale of AMPKindependent effects of metformin. J. Clin. Invest. 120:2267-2270. https://doi.org/10.1172/JCI43661.

Miyazawa, K., T. Hondo, T. Kanaya, S. Tanaka, I. Takakura, W. Itani, M. T. Rose, H. Kitazawa, T. Yamaguchi, and H. Aso. 2010. Characterization of newly established bovine intestinal epithelial cell line. Histochem. Cell Biol. 133:125-134. https://doi.org/10 .1007/s00418-009-0648-3.

Murondoti, A., R. Jorritsma, A. C. Beynen, T. Wensing, and M. J. H. Geelen. 2004. Activities of the enzymes of hepatic gluconeogenesis in periparturient dairy cows with induced fatty liver. J. Dairy Res. 71:129-134. https://doi.org/10.1017/S0022029904000020.

Rusu, D., S. Loret, O. Peulen, J. Mainil, and G. Dandrifosse. 2005. Immunochemical, biomolecular and biochemical characterization of bovine epithelial intestinal primocultures. BMC Cell Biol. 6:42. https://doi.org/10.1186/1471-2121-6-42. 
Schmitt, M. G. Jr., K. H. Soergel, C. M. Wood, and J. J. Steff. 1977. Absorption of short-chain fatty acids from the human ileum. Am. J. Dig. Dis. 22:340-347. https://doi.org/10.1007/BF01072192.

Tiraby, C., and D. Langin. 2005. PGC-1 alpha, a transcriptional coactivator involved in metabolism. Med. Sci. (Paris) 21:49-54.

van Schaftingen, E., and I. Gerin. 2002. The glucose-6-phosphatase system. Biochem. J. 362:513-532. https://doi.org/10.1042/ bj3620513.

Wang, L. F., G. Q. Yang, S. Yang, G. Y. Yang, M. Li, H. S. Zhu, Y. Y. Wang, L. Q. Han, R. Y. Liu, S. D. Jia, and F. Song. 2015. Alteration of factors associated with hepatic gluconeogenesis in response to acute lipopolysaccharide in dairy goat. J. Anim. Sci. 93:2767-2777. https://doi.org/10.2527/jas.2014-8718.

White, H. M., S. L. Koser, and S. S. Donkin. 2012. Gluconeogenic enzymes are differentially regulated by fatty acid cocktails in MadinDarby bovine kidney cells. J. Dairy Sci. 95:1249-1256. https://doi .org/10.3168/jds.2011-4644.

Wiese, T. J., D. O. Lambeth, and P. D. Ray. 1991. The intracellular distribution and activities of phosphoenolpyruvate carboxykinase isozymes in various tissues of several mammals and birds. Comp. Biochem. Physiol. B 100:297-302. https://doi.org/10.1016/0305 -0491(91)90378-Q.

Yoon, J. C., P. Puigserver, G. Chen, J. Donovan, Z. Wu, J. Rhee, G. Adelmant, J. Stafford, C. R. Kahn, D. K. Granner, C. B. Newgard, and B. M. Spiegelman. 2001. Control of hepatic gluconeogenesis through the transcriptional coactivator PGC-1. Nature 413:131-138. https://doi.org/10.1038/35093050.
Zhan, K., M. Jiang, X. Gong, and G. Zhao. 2018. Effect of short-chain fatty acids on the expression of genes involved in short-chain fatty acid transporters and inflammatory response in goat jejunum epithelial cells. In Vitro Cell. Dev. Biol. Anim. 54:311-320. https:// doi.org/10.1007/s11626-017-0226-2.

Zhan, K., M. Lin, M. M. Liu, Y. N. Sui, and G. Q. Zhao. 2017. Establishment of primary bovine intestinal epithelial cell culture and clone method. In Vitro Cell. Dev. Biol. Anim. 53:54-57. https:// doi.org/10.1007/s11626-016-0082-5.

Zhang, Q., S. L. Koser, and S. S. Donkin. 2016. Propionate induces mRNA expression of gluconeogenic genes in bovine calf hepatocytes. J. Dairy Sci. 99:3908-3915. https://doi.org/10.3168/jds 2015-10312.

Zhou, Y., R. M. Akers, and H. Jiang. 2008. Growth hormone can induce expression of four major milk protein genes in transfected MAC-T cells. J. Dairy Sci. 91:100-108. https://doi.org/10.3168/ jds.2007-0509.

\section{ORCIDS}

Kang Zhan () https://orcid.org/0000-0001-7810-0763

Tian Yu Yang @ https://orcid.org/0000-0001-9845-637X

Yinyin Chen () https://orcid.org/0000-0001-7249-5506

Mao Cheng Jiang ( https://orcid.org/0000-0002-4533-101X

Guo Qi Zhao @ https://orcid.org/0000-0001-8020-2400 